\title{
SECOND AND THIRD ORDER BOUNDARY VALUE PROBLEMS
}

\author{
KEITH SCHRADER
}

AbSTRACT. In this paper some existence theorems for solutions on $(-\infty,+\infty)$ of second and third order differential equations of the form $y^{\prime \prime}=f\left(t, y, y^{\prime}\right)$ and $y^{\prime \prime \prime}=f\left(t, y, y^{\prime}, y^{\prime \prime}\right)$ are established. The hypotheses include the assumption that $f$ is continuous, that solutions of initial value problems extend to $(-\infty,+\infty)$ and that certain boundary value problems have no more than one solution.

1. Introduction. Let $t, y, z$ and $w$ be variables in $R$, the real numbers, and $f$ be a real valued function. We will assume subsets of the following conditions as needed for second order equations.

$\left(\mathrm{A}_{2}\right) f$ is a continuous function of $(t, y, z)$ for $(t, y, z) \in R^{3}$.

$\left(\mathrm{B}_{2}\right)$ If $y_{1}$ and $y_{2}$ are solutions of the differential equation

$$
y^{\prime \prime}=f\left(t, y, y^{\prime}\right)
$$

on $\left[t_{1}, t_{2}\right]$ where $t_{1}<t_{2}$ such that $y_{1}\left(t_{i}\right)=y_{2}\left(t_{i}\right)$ for $i=1,2$ then $y_{1}(t)=y_{2}(t)$ for $t \in\left[t_{1}, t_{2}\right]$.

$\left(\mathrm{C}_{2}\right)$ All solutions of all initial value problems for (1) extend throughout $(-\infty,+\infty)$.

For third order equations we will impose conditions from among the following.

$\left(\mathrm{A}_{3}\right) f$ is a continuous function of $(t, y, z, w)$ for $(t, y, z, w) \in R^{4}$.

$\left(B_{3}\right)$ If $y_{1}$ and $y_{2}$ are solutions of the differential equation

$$
y^{\prime \prime \prime}=f\left(t, y, y^{\prime}, y^{\prime \prime}\right)
$$

on $\left[t_{1}, t_{3}\right]$ where $t_{1}<t_{2}<t_{3}$ such that $y_{1}\left(t_{i}\right)=y_{2}\left(t_{i}\right)$ for $i=1,2,3$ then $y_{1}(t)=y_{2}(t)$ for $t \in\left[t_{1}, t_{3}\right]$.

$\left(\mathrm{C}_{3}\right)$ All solutions of all initial value problems for (2) extend throughout $(-\infty,+\infty)$.

In a paper [5], Khalikov considers the equation (1) where

$$
\begin{aligned}
f\left(t, y, y^{\prime}\right) & =F\left(t, x, y^{\prime}\right), & & y<x, \\
& =F\left(t, y, y^{\prime}\right), & & x \leqq y \leqq z, \\
& =F\left(t, z, y^{\prime}\right), & & y>z,
\end{aligned}
$$

Received by the editors December 28, 1970 and, in revised form, May 24, 1971.

AMS 1970 subject classifications. Primary 34B15, 34B10.

Key words and phrases. Nonlinear, boundary value problems, second order, third order.

(c) American Mathematical Society 1972 
and $x, z$ are certain solutions of (1) satisfying the inequality $x(t)<z(t)$ for $-\infty<t<+\infty$. The function $F$ is continuous in the domain $G$ $\left(x \leqq y \leqq z,-\infty<t, y^{\prime}<+\infty\right)$ and satisfies a Lipschitz condition with respect to $y, y^{\prime}$ in any bounded domain $P \subset G$. On the assumption that the boundary problem (1) with boundary conditions

$$
\begin{aligned}
y\left(t_{0}\right)=c_{0}, & y\left(t_{0}+h\right)=c_{1}, \\
c_{0} \in\left[x\left(t_{0}\right), z\left(t_{0}\right)\right], & c_{1} \in\left[x\left(t_{0}+h\right), z\left(t_{0}+h\right)\right],
\end{aligned}
$$

has not more than one solution for fixed $c_{0}, c_{1}$ and $t_{0}, h \in(-\infty,+\infty)$, Khalikov claims the following theorem is valid.

THEOREM 1.1. At least one solution y of (1) satisfying the inequality

$$
x(t)<y(t)<z(t), \quad-\infty<t<+\infty,
$$

passes through each point $\left(t_{0}, p_{0}\right)$ where $t_{0} \in(-\infty,+\infty), p_{0} \in\left(x\left(t_{0}\right), z\left(t_{0}\right)\right)$.

Because of the assumed Lipschitz condition on any bounded domain $P \subset G$, solutions of initial value problems for (1) of the form $y\left(t_{0}\right)=p_{0}$, $y^{\prime}\left(t_{0}\right)=p_{1}$ where $t_{0} \in(-\infty,+\infty), p_{0} \in\left(x\left(t_{0}\right), z\left(t_{0}\right)\right)$ are unique. In Khalikov's proof of Theorem 1 there appears to be an assumption that solutions of initial value problems for (1) extend to the interval $(-\infty,+\infty)$. Also, in the proof of the theorem he claims that the two point boundary value problem (1), (3) is solvable for sufficiently small $|h|$. The following example $[1$, p. 1059] shows that under the hypotheses of Theorem 1 neither of the properties mentioned above need be satisfied.

Consider the equation

$$
y^{\prime \prime}=-18 t\left(y^{\prime}\right)^{4}=F\left(t, y, y^{\prime}\right)
$$

with $x(t)=-1, z(t)=1$. All the hypotheses of Khalikov's Theorem 1 are satisfied but $y(t)=t^{1 / 3}$ is a solution of (4) on $(0,+\infty)$ with initial conditions

$$
y(1 / 2)=(1 / 2)^{1 / 3}, \quad y^{\prime}(1 / 2)=(1 / 3)(1 / 2)^{-2 / 3}
$$

whose maximal interval of existence is $(0,+\infty)$ not $(-\infty,+\infty)$. Furthermore the boundary value problem for (4) with boundary conditions

$$
y(-h / 2)=(-h / 2)^{1 / 3}, \quad y(h / 2)=(h / 2)^{1 / 3}, \quad 0<h<2,
$$

is not solvable for $|h|$ sufficiently small since it can be shown that if a solution of (4), (5) exists it must be $y(t)=t^{1 / 3}$ which is not a solution on $[-h / 2, h / 2]$. See [1, p. 1059] for more detail concerning this example.

In $\S 2$ of this paper we show that Khalikov's theorem is correct if our property $\left(C_{2}\right)$ is assumed i.e. if solutions of all initial value problems extend throughout $(-\infty,+\infty)$. In addition we remove the requirement that 
a Lipschitz condition be satisfied. We do not answer the question of whether Khalikov's theorem is correct as originally stated. This question would seem to be related to a question posed by the author in [6, p. 1012]. In $\S 3$ we show that a generalization of this result for second order equations holds for third order equations as well.

2. Second order equations. In this section we establish the following result.

THEOREM 2.1. If $\left(\mathrm{A}_{2}\right),\left(\mathrm{B}_{2}\right)$ and $\left(\mathrm{C}_{2}\right)$ hold and $x, z$ are in $C^{2}(-\infty,+\infty)$ with $x(t) \leqq z(t)$ and $x, z$ are solutions of $(1)$ then for every point $\left(t_{0}, p_{0}\right)$ with $x\left(t_{0}\right) \leqq p_{0} \leqq z\left(t_{0}\right)$ there is a solution $y$ of $(1)$ on $(-\infty,+\infty)$ such that $x(t) \leqq y(t) \leqq z(t)$ and $y\left(t_{0}\right)=p_{0}$. If solutions of initial value problems for (1) are unique then we can conclude that $x(t)<y(t)<z(t)$ provided $x\left(t_{0}\right)<p_{0}<$ $z\left(t_{0}\right)$.

Proof. If $p_{0}=x\left(t_{0}\right)$ or $p_{0}=z\left(t_{0}\right)$ we are done, so suppose $x\left(t_{0}\right)<p_{0}<$ $z\left(t_{0}\right)$. By [7, Theorem 6.1] every two point boundary value problem has a solution. Let $\left\{u_{n}\right\},\left\{v_{n}\right\},\left\{w_{n}\right\}$ and $\left\{y_{n}\right\}$ be sequences of solutions of (1) satisfying the boundary conditions

$$
\begin{gathered}
u_{n}\left(t_{0}\right)=v_{n}\left(t_{0}\right)=w_{n}\left(t_{0}\right)=y_{n}\left(t_{0}\right)=p_{0}, \quad u_{n}\left(t_{0}+n\right)=z\left(t_{0}+n\right), \\
v_{n}\left(t_{0}+n\right)=x\left(t_{0}+n\right), \quad w_{n}\left(t_{0}-n\right)=z\left(t_{0}-n\right), \\
y_{n}\left(t_{0}-n\right)=x\left(t_{0}-n\right) .
\end{gathered}
$$

The sequences $\left\{u_{n}^{\prime}\left(t_{0}\right)\right\},\left\{v_{n}^{\prime}\left(t_{0}\right)\right\},\left\{w_{n}^{\prime}\left(t_{0}\right)\right\}$ and $\left\{y_{n}^{\prime}\left(t_{0}\right)\right\}$ are monotone and converge, so by [2, Theorem $3.2, \mathrm{p}$. 14] there exist solutions $u, v, w$ and $y$ of $(1)$ on $(-\infty,+\infty)$ and subsequences of $\left\{u_{n}\right\},\left\{v_{n}\right\},\left\{w_{n}\right\}$ and $\left\{y_{n}\right\}$ which we again denote by $\left\{u_{n}\right\},\left\{v_{n}\right\},\left\{w_{n}\right\}$ and $\left\{y_{n}\right\}$ such that

$$
\begin{array}{llll}
u_{n}(t) \rightarrow u(t), & u_{n}^{\prime}(t) \rightarrow u^{\prime}(t), & v_{n}(t) \rightarrow v(t), & v_{n}^{\prime}(t) \rightarrow v^{\prime}(t), \\
w_{n}(t) \rightarrow w(t), & w_{n}^{\prime}(t) \rightarrow w^{\prime}(t), & y_{n}(t) \rightarrow y(t), & y_{n}^{\prime}(t) \rightarrow y^{\prime}(t),
\end{array}
$$

as $n \rightarrow+\infty$, uniformly on compact subintervals of $(-\infty,+\infty)$. We note that $x(t) \leqq v(t) \leqq u(t) \leqq z(t)$ for $t_{0} \leqq t<+\infty$ and that $x(t) \leqq y(t) \leqq w(t) \leqq$ $z(t)$ for $-\infty<t \leqq t_{0}$.

It is not hard to show that either one of the solutions $u, v, w$ or $y$ must satisfy the conclusion of the theorem or else one of $y^{\prime}\left(t_{0}\right), w^{\prime}\left(t_{0}\right)$ equals one of $u^{\prime}\left(t_{0}\right), v^{\prime}\left(t_{0}\right)$ and we can "paste" these two solutions together at $t_{0}$ to get a solution on $(-\infty,+\infty)$. The details are similar to the corresponding details in the proof of Theorem 3.1 to follow so they are omitted here. The proof of the last sentence of the theorem is immediate.

3. Third order equations. We wish to establish the following generalization of the result already obtained for second order equations. 
TheOREM 3.1. If $\left(\mathrm{A}_{3}\right),\left(\mathrm{B}_{3}\right)$ and $\left(\mathrm{C}_{3}\right)$ hold and $x, z$ are in $C^{3}(-\infty,+\infty)$ with $x(t) \leqq z(t)$ for $-\infty<t \leqq t_{0}, z(t) \leqq x(t)$ for $t_{0} \leqq t<+\infty$ and $x, z$ are solutions of (2) then for every point $\left(t_{0}, p_{0}, p_{1}\right)$ with $x\left(t_{0}\right)=p_{0}=z\left(t_{0}\right)$, $z^{\prime}\left(t_{0}\right) \leqq p_{1} \leqq x^{\prime}\left(t_{0}\right)$ there is a solution $y$ of $(2)$ on $(-\infty,+\infty)$ such that $x(t) \leqq y(t) \leqq z(t)$ for $-\infty<t \leqq t_{0}, z(t) \leqq y(t) \leqq x(t)$ for $t_{0} \leqq t<+\infty$ and $y\left(t_{0}\right)=p_{0}, y^{\prime}\left(t_{0}\right)=p_{1}$. If solutions of initial value problems for (2) are unique we can conclude that $x(t)<y(t)<z(t)$ for $-\infty<t<t_{0}, z(t)<y(t)<x(t)$ for $t_{0}<t<+\infty$ provided $z^{\prime}\left(t_{0}\right)<p_{1}<x^{\prime}\left(t_{0}\right)$.

Proof. If $p_{1}=x^{\prime}\left(t_{0}\right)$ or $p_{1}=z^{\prime}\left(t_{0}\right)$ we are done, so suppose $z^{\prime}\left(t_{0}\right)<p_{1}<$ $x^{\prime}\left(t_{0}\right)$. By [4, Theorem 3.1] any fixed two point boundary value problem for (2) with boundary conditions

$$
y\left(t_{1}\right)=\alpha, \quad y^{\prime}\left(t_{1}\right)=\beta, \quad y\left(t_{2}\right)=\gamma,
$$

or

$$
y\left(t_{1}\right)=\alpha, \quad y\left(t_{2}\right)=\beta, \quad y^{\prime}\left(t_{2}\right)=\gamma,
$$

where $t_{1}<t_{2}$, has at most one solution. By [3, Theorem 1] all two point boundary value problems of the form (2), (6) or (2), (7) have solutions. Let $\left\{u_{n}\right\}$ be the sequence of solutions of (2) satisfying the boundary conditions

$$
u_{n}\left(t_{0}\right)=p_{0}, \quad u_{n}^{\prime}\left(t_{0}\right)=p_{1}, \quad u_{n}\left(t_{0}+n\right)=x\left(t_{0}+n\right),
$$

and let $\left\{v_{n}\right\}$ be the sequence of solutions of (2) satisfying

$$
v_{n}\left(t_{0}\right)=p_{0}, \quad v_{n}^{\prime}\left(t_{0}\right)=p_{1}, \quad v_{n}\left(t_{0}+n\right)=z\left(t_{0}+n\right) .
$$

It follows from $\left(\mathrm{B}_{3}\right)$ and the uniqueness of two point boundary value problems for (2) that without loss of generality we may assume

$$
z(t) \leqq v_{n}(t) \leqq v_{n+1}(t) \leqq u_{n+1}(t) \leqq u_{n}(t) \leqq x(t)
$$

for $t_{0} \leqq t \leqq t_{0}+n$ and that

$$
v_{n}(t) \leqq v_{n+1}(t) \leqq u_{n+1}(t) \leqq u_{n}(t)
$$

for $t>t_{0}+n$. Similarly we may assume, possibly by renaming solutions, that

$$
v_{n}(t) \leqq v_{n+1}(t) \leqq u_{n+1}(t) \leqq u_{n}(t)
$$

for $t \leqq t_{0}$. From these inequalities we conclude that

$$
v_{n}^{\prime \prime}\left(t_{0}\right) \leqq v_{n+1}^{\prime \prime}\left(t_{0}\right) \leqq u_{n+1}^{\prime \prime}\left(t_{0}\right) \leqq u_{n}^{\prime \prime}\left(t_{0}\right) .
$$

The sequences $\left\{v_{n}^{\prime \prime}\left(t_{0}\right)\right\}$ and $\left\{u_{n}^{\prime \prime}\left(t_{0}\right)\right\}$ converge, so by [2, Theorem 3.2 , p. 14] there exist solutions $v, u$ of $(2)$ on $(-\infty,+\infty)$ and subsequences of 
$\left\{v_{n}\right\}$ and $\left\{u_{n}\right\}$ which we again denote by $\left\{v_{n}\right\}$ and $\left\{u_{n}\right\}$ such that

$$
\begin{array}{rlrl}
v_{n}(t) & \rightarrow v(t), & v_{n}^{\prime}(t) \rightarrow v^{\prime}(t), & v_{n}^{\prime \prime}(t) \rightarrow v^{\prime \prime}(t), \\
u_{n}(t) \rightarrow u(t), & u_{n}^{\prime}(t) \rightarrow u^{\prime}(t), & u_{n}^{\prime \prime}(t) \rightarrow u^{\prime \prime}(t),
\end{array}
$$

as $n \rightarrow+\infty$, uniformly on compact subintervals of $(-\infty,+\infty)$. We note that $z(t) \leqq v(t) \leqq u(t) \leqq x(t)$ for $t_{0} \leqq t<+\infty$. Also, we have that $v(t) \leqq u(t)$ for $-\infty<t<t_{0}$. By construction we must have $x(t) \leqq u(t)$ and $v(t) \leqq z(t)$ for $-\infty<t \leqq t_{0}$.

If $u(t) \leqq z(t)$ or $v(t) \geqq x(t)$ for $-\infty<t \leqq t_{0}$ we are done. Thus let $\tau_{1}, \tau_{2}$ be chosen so that

$$
\begin{aligned}
& \tau_{1}=\inf \left\{\tau: v(t) \geqq x(t) \text { for } \tau \leqq t \leqq t_{0}\right\}, \\
& \tau_{2}=\inf \left\{\tau: u(t) \leqq z(t) \text { for } \tau \leqq t \leqq t_{0}\right\}
\end{aligned}
$$

Let $\left\{w_{n}\right\}$ be the sequence of solutions of (2) satisfying the boundary conditions

$$
w_{n}\left(t_{0}\right)=p_{0}, \quad w_{n}^{\prime}\left(t_{0}\right)=p_{1}, \quad w_{n}\left(t_{0}-n\right)=z\left(t_{0}-n\right),
$$

and let $\left\{y_{n}\right\}$ be the sequence of solutions of (2) with boundary conditions

$$
y_{n}\left(t_{0}\right)=p_{0}, \quad y_{n}^{\prime}\left(t_{0}\right)=p_{1}, \quad y_{n}\left(t_{0}-n\right)=x\left(t_{0}-n\right) .
$$

It follows from $\left(\mathrm{B}_{3}\right)$ and the uniqueness of two point boundary value problems for (2) that if $N$ is chosen so that $t_{0}-N<\min \left\{\tau_{1}, \tau_{2}\right\}$ then for $n>N$ we may assume without loss of generality that

$$
x(t) \leqq y_{n}(t) \leqq y_{n+1}(t) \leqq w_{n+1}(t) \leqq w_{n}(t) \leqq z(t)
$$

for $t_{0}-n \leqq t \leqq t_{0}$ and that

$$
v(t) \leqq y_{n}(t) \leqq y_{n+1}(t) \leqq w_{n+1}(t) \leqq w_{n}(t) \leqq u(t)
$$

for $t \leqq t_{0}$. Similarly we may assume that

$$
v(t) \leqq y_{n}(t) \leqq y_{n+1}(t) \leqq w_{n+1}(t) \leqq w_{n}(t) \leqq u(t)
$$

for $t_{0} \leqq t<+\infty$. From these inequalities we conclude that

$$
v^{\prime \prime}\left(t_{0}\right) \leqq y_{n}^{\prime \prime}\left(t_{0}\right) \leqq y_{n+1}^{\prime \prime}\left(t_{0}\right) \leqq w_{n+1}^{\prime \prime}\left(t_{0}\right) \leqq w_{n}^{\prime \prime}\left(t_{0}\right) \leqq u^{\prime \prime}\left(t_{0}\right) .
$$

The sequences $\left\{w_{n}^{\prime \prime}\left(t_{0}\right)\right\},\left\{y_{n}^{\prime \prime}\left(t_{0}\right)\right\}$ converge, so by [2, Theorem 3.2, p. 14] there exist solutions $w, y$ of $(2)$ on $(-\infty,+\infty)$ and subsequences of $\left\{w_{n}\right\}$ and $\left\{y_{n}\right\}$ which we again denote by $\left\{w_{n}\right\}$ and $\left\{y_{n}\right\}$ such that

$$
\begin{array}{rlrl}
w_{n}(t) & \rightarrow w(t), & w_{n}^{\prime}(t) \rightarrow w^{\prime}(t), & w_{n}^{\prime \prime}(t) \rightarrow w^{\prime \prime}(t), \\
y_{n}(t) \rightarrow y(t), & y_{n}^{\prime}(t) \rightarrow y^{\prime}(t), & y_{n}^{\prime \prime}(t) \rightarrow y^{\prime \prime}(t),
\end{array}
$$

as $n \rightarrow+\infty$, uniformly on compact subintervals of $(-\infty,+\infty)$. We note 
that $x(t) \leqq y(t) \leqq w(t) \leqq z(t)$ for $-\infty<t \leqq t_{0}$ and by $\left(\mathrm{B}_{3}\right)$ and the uniqueness of two point boundary value problems for (2) we may assume without loss of generality that $z(t) \leqq y(t) \leqq w(t) \leqq x(t)$ for $t_{0} \leqq t<+\infty$ so we are done since either $y$ or $w$ satisfies the conclusion of the theorem. The proof of the last sentence of the theorem follows from the uniqueness of solutions of two point boundary value problems for (2).

\section{REFERENCES}

1. J. W. Bebernes, A subfunction approach to a boundary value problem for ordinary differential equations, Pacific J. Math. 13 (1963), 1053-1066. MR 27 \#5951.

2. P. Hartman, Ordinary differential equations, Wiley, New York, 1964. MR 30 \#1270.

3. L. Jackson and $\mathrm{K}$. Schrader, Existence and uniqueness of solutions of boundary value problems for third order differential equations, J. Differential Equations 9 (1971), 46-54.

4. —_, Subfunctions and thirdorder differential inequalities, J. Differential Equations 8 (1970), 180-194. MR 41 \#2175.

5. E. G. Halikov, The existence of bounded solutions of a differential equation of the second order, Differential Equations 2 (1966), 865-866.

6. K. W. Schrader, A note on second order differential inequalities, Proc. Amer. Math. Soc. 19 (1968), 1007-1012. MR 38 \#2416.

7. —-, Existence theorems for second order boundary value problems, J. Differential Equations 5 (1969), 572-584. MR 39 \#532.

Department of Mathematics, University of Missouri, Columbia, Missouri 65201 